\title{
Analysis of spatial and temporal changes of soil erosion in Anning river basin
}

\author{
Yao Kun $^{1 *}$, Chen Jian-Bin ${ }^{1}$, Yang Yong-Sheng ${ }^{2}$, Zhang Yong ${ }^{3}$, Liao Cheng-Hao ${ }^{1}$ \\ ${ }^{1}$ School of resources and Environment, Xichang University, Xichang, Sichuan 615000; \\ 2 State Grid Liangshan Power Supply Company, Xichang, Sichuan 615000; \\ ${ }^{3}$ Liangshan Four Brothers Agricultural Development Limited company, Xichang, Sichuan 615000
}

\begin{abstract}
Anning River basin as an important soil erosion monitoring and reserve in Sichuan Province. It is of great significance to grasp the temporal and spatial changes of soil erosion in this area in time to realize the comprehensive treatment of regional soil erosion. Based on the revision of the general soil erosion equation (RUSLE), the present situation of soil erosion erosion in 1995-2015 years in this area was monitored, and the classification was completed according to the national grading criteria, and the following results were mainly achieved:(1) Soil erosion in Anning river basin as a whole presents a low gradient change in the eastern High West.(2) The proportion of raster in soil erosion area of each grade also showed different structural differences, which showed that the degree of micro $>$ Mild $>$ Moderate $>$ Strong $>$ Extremely $>$ severe, and the proportion of raster in mild and below intensity erosion area reached more than $80 \%$, and the whole basin was at mildly below erosion level.(3)One-dimensional linear regression analysis shows, within 20 years, about $90 \%$ of the raster cell slope in this area is negative, the overall change trend of soil erosion in this area shows a significant improvement
\end{abstract}

Soil erosion is one of the natural disasters that affect social and economic development and threaten human survival, the innate natural environment of the region determines the severity of soil erosion, at the same time, human activity is an important factor contributing to its change. The frequent occurrence of soil erosion will not only cause environmental problems such as declining land productivity, river blockage and flash flood outbreak, but also aggravate the fragility of regional ecological environment and pose a threat to the sustainable development of human beings.

Experts and scholars at home and abroad have carried out a lot of research on regional soil erosion and obtained many research results. Wischmeier and $\mathrm{Smith}^{[1]}$ put forward that the general equation of soil erosion (USLE) has achieved great benefits and has been widely recognized. Chen Mei Qi and others ${ }^{[2]}$ used the soil loss equation (CSLE) in China to study the law of soil and water loss in Guizhou province. Yi Kai and others ${ }^{[3]}$ According to the United States Department of Agriculture revised RUSLE equation on the soil erosion of Chaoyang in Liaoning Province. Cao Sheng ${ }^{[4]}$ assessment of Ningxiang soil using USLE model. Wang Jiao and others ${ }^{[5]}$ completed the spatial analysis of soil erosion sensitivity in Taihang mountain area. Li Dalong and other ${ }^{[6]}$ to evaluate the soil erosion sensitivity of yili.

Anning River basin plays an important role in ecological environmental protection and construction in the province. However, due to the limitation of natural conditions such as high altitude and complicated geological conditions, etc. In addition, unreasonable exploitation and utilization of natural resources such as land, water and minerals. It has become the key area of ecological protection and soil erosion monitoring in southwest Sichuan. In order to make up for this vacancy, the paper studies the combination of RS, GIS technology and modified general soil erosion (RUSLE) model to monitor the soil and water loss in this area for 1995-2015 years, and explores and analyzes its spatiotemporal variation law in order to provide scientific theoretical reference for the management of regional soil erosion.

\section{DATA}

According to the RUSLE model, the data of each component factor is obtained, and the data description and source are studied (Table 1).

\footnotetext{
* Corresponding author:jiangshan996@126.com.
} 
Table 1. Research data types and sources

\begin{tabular}{|c|c|}
\hline Name & Data sources \\
\hline $\begin{array}{l}\text { Digital Elevation Model (DEM) in watershed area, resolution of } \\
\qquad 30 \times 30 \mathrm{~m}\end{array}$ & $\begin{array}{c}\text { The data set is provided by Geospatial Data Cloud site, } \\
\text { Computer Network Information Center, Chinese Academy of } \\
\text { Sciences. (http://www.gscloud.cn) }\end{array}$ \\
\hline $\begin{array}{l}\text { 1:1000000 soil type vector data, including various sizes of sand } \\
\text { grains, powder particles, organic matter content and other } \\
\text { information }\end{array}$ & China Soil Database \\
\hline $\begin{array}{l}\text { Rainfall data for each month and year counted by meteorological } \\
\text { stations in and around the study area }\end{array}$ & $\begin{array}{l}\text { China meteorological Data Science sharing network } \\
\text { (http://data.cma.cn/) }\end{array}$ \\
\hline $\begin{array}{l}\text { Watershed Area 1:100,000 Land Use type remote sensing } \\
\text { interpretation results data, } 1995 \text { and } 2000 \text { as vector results, } \\
\text { Other issues of raster data for } 30 \times 30 \mathrm{~m}\end{array}$ & $\begin{array}{c}\text { Data for } 1995 \text { and } 2015 \text { are derived from Cold and Arid } \\
\text { Regions Sciences Data Center at Lanzhou } \\
\text { (http://westdc.westgis.ac.cn); others from Resource and } \\
\text { Environment Data Cloud Platform } \\
\text { (http://www.resdc.cn) }\end{array}$ \\
\hline
\end{tabular}

\section{Research Methods}

\subsection{USLE Model}

Wischmeier and Smith established a general equation of soil erosion (USLE) through a large number of experiments, and later modified to form the RUSLE equation, the model has been widely used in academic circles to calculate the amount of soil erosion in various regions. The model is as follows.

$$
A=R \times L S \times K \times C \times P
$$

In the formula: $\mathrm{A}$ is soil erosion modulus $\mathrm{t} /\left(\mathrm{hm}^{2} \times \mathrm{a}\right), \mathrm{R}$ is rainfall erosion factor $\left(\mathrm{MJ} \cdot \mathrm{mm} / \mathrm{hm}^{2} \cdot \mathrm{a} \cdot \mathrm{h}\right)$, LS is slope and slope length factor, $\mathrm{K}$ is soil erosive factors, $\mathrm{C}$ is vegetation cover factor and $\mathrm{P}$ is soil and water conservation factors.

\subsection{Rainfall erosion Force factor}

Precipitation erosion force is the main external force affecting the degree of soil erosion. and this study selects the classical model proposed by Wischmeier ${ }^{[1]}$ to calculate. The model is as follows.

$$
R=\sum_{\mathrm{i}=1}^{12} 1.735 \times 10^{\left(1.5 \times \log \left(\frac{p_{i}^{2}}{p}\right)\right)-0.8188}
$$

In the formula: $P_{i}$ is monthly rainfall, $P$ is annual rainfall. In this study, the model (2) was used to calculate the rainfall erosion force of each site in different years, and its spatial interpolation was accomplished by using the inverse distance weight model.

\subsection{LS is slope and slope length factor}

The size of $L$ value has a significant interaction with the rate of surface runoff, typically, the more severe the mild the soil erosion in the long slope area. Slope, as one of the important indexes of terrain change, can objectively characterize the effect of topography on soil erosion. The calculation of slope length in the study adopts the Chinese calculation model proposed by Liu Baoyun and others $^{[7]}$. Slope factor using the calculation model of Southwest Mountain Area proposed by Liu Bintao and others $^{[8]}$. The model is as follows.

$$
S= \begin{cases}10.8 \sin \theta+0.3 & \left(\theta \leqslant 5^{\circ}\right) \\ 16.8 \sin \theta-0.5 & \left(5^{\circ}<\theta \leqslant 10^{\circ}\right) \\ 20.204 \sin \theta-0.1204 & \left(10^{\circ}<\theta \leqslant 25^{\circ}\right) \\ 29.585 \sin \theta-5.6079 & \left(\theta>25^{\circ}\right)\end{cases}
$$

In the formula: $\mathrm{S}$ is the slope factor, $\mathrm{L}$ is the slope length factor, $\theta$ is the ground slope, $\lambda$ is theslope length value, $\mathrm{m}$ is the slope factor index.

$$
L=(\lambda / 22.13)^{m}=\left\{\begin{array}{cc}
m=0.2 & \theta \leqslant 1^{\circ} \\
m=0.3 & 1^{\circ}<\theta \leqslant 3^{\circ} \\
m=0.4 & 3^{\circ}<\theta \leqslant 5^{\circ} \\
m=0.5 & \theta>5^{\circ}
\end{array}\right.
$$

\subsection{Soil erosive factors}

Soil erosive can reflect the sensitivity of external forces such as precipitation to its stripping. It is one of the important indexes to measure soil erosion in the region, and the data source based on 1:100 million soil data is studied, and the $\mathrm{K}$ value is calculated by combining EPIC model $^{[3,4]}$. The model is as follows.

$$
K=\left\{\begin{array}{l}
{\left[0.2+0.3 e^{-0.0256 S A N(1-S L / 100)}\right] \times\left[\frac{S I L}{C L A+S I L}\right]^{0.3} \times} \\
{\left[1.0-\frac{0.25 C}{C+e^{(3.72-2.95 C)}}\right] \times 1.0-\frac{0.7 S N I}{S N I+\mathrm{e}^{(-5.51+22.9 S N)}}}
\end{array}\right\}
$$

In the formula: $\mathrm{K}$ is soil erosive factors $(\mathrm{t} / \mathrm{MJ} \cdot \mathrm{mm})$, SAN is sand granules, SLA is powder granules, CLA is sticky granules, $\mathrm{C}$ is indicates organic matter, $\mathrm{SN} 1=1$ SAN/100.

\subsection{Vegetation and soil and water conservation factors}

The research completes the determination of $\mathrm{C}$ and $\mathrm{P}$ values by referring to the achievements ${ }^{[8-12]}$ (Table 2).. 
Table 2. $\mathrm{C}$ and $\mathrm{P}$ value determination coefficient

\begin{tabular}{cccccc}
\hline Surface Overlay Name & P & C & Surface Overlay Name & P & C \\
\hline Paddy & 0.01 & 0.18 & Lake & 0 & 0 \\
Dryland & 0.4 & 0.31 & Reservoirs, pits and ponds & 0 & 0 \\
Woodland & 1 & 0.003 & Permanent Glacial Snow Cover & 0 & 0 \\
Shrubwood & 1 & 0.01 & Beach land & 0 & 0 \\
Sparse woodland & 1 & 0.05 & Urban construction land & 0 & 0 \\
Other forest land & 0.6 & 0.05 & Rural settlements & 0 & 0 \\
Highly Covered Grassland & 1 & 0.002 & Other Construction Land & 0 & 0 \\
Moderate Covered Grassland & 1 & 0.03 & Sand & 0 & 0 \\
Low Covered Grassland & 1 & 0.1 & Bare land & 0.4 & 1 \\
Rivers & 0 & 0 & & & \\
\hline
\end{tabular}

\section{RESULTS AND ANALYSIS}

\subsection{Spatial Distribution Characteristics}

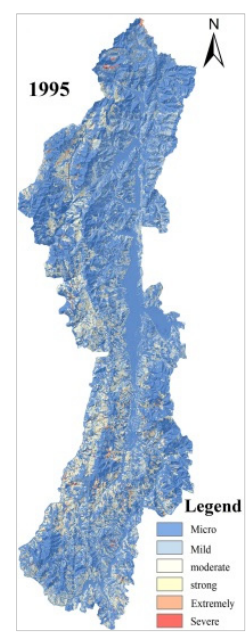

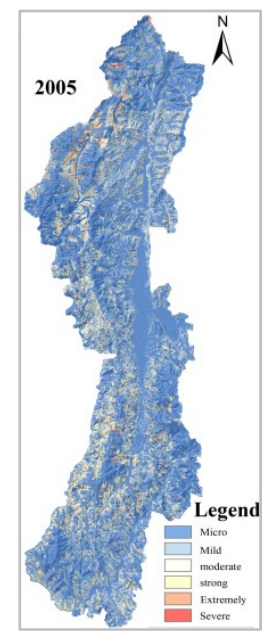

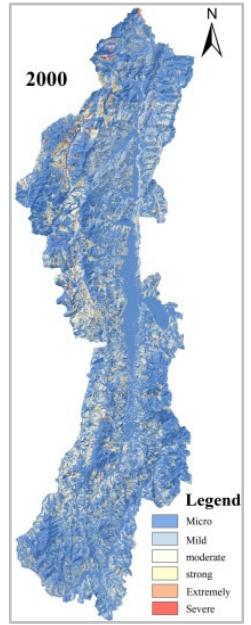

The research combines RS, GIS technology and RUSLE model to calculate the soil erosion quantity in different periods of the Anning River basin in 1995-2015, and to complete the delimitation of soil erosion grade in different years according to national standards ${ }^{[12]}$ (Fig. 1).

Fig.1 Soil erosion intensity grading in Anning River basin in 1995-2015

According to Figure 5: Soil erosion in the Anning River basin shows a gradient change of West high east and Low, the intensity of soil erosion in the western region is higher and wider than that in the east. In addition, the intensity erosion areas of each level also show obvious distribution differences in spatial distribution. The proportion of extremely strong and Severe soil erosion areas in the whole basin is only about $3 \%$, and is mainly concentrated in the northwest of Mianning County, and in the western region of Xichang. The land landscape in these areas is mainly sparse woodland and dryland, while the geomorphological type is mainly alpine and polar Alpine, the terrain is steep, the topography fluctuation difference is obvious, the slope length and the slope factor data are also larger, the regional soil erosion is relatively serious. Moderate and strongly eroded areas account for about $12 \%$ of the entire basin, most of which are concentrated on both sides of the Anning River Valley Plain, where the main geomorphological types and land use patterns are dominated by shrubbery, sparse woodland and cropland, with the highest vegetation cover and the most complex ecosystem in the region. It is a key buffer area protection zone for regional soil erosion. The proportion of micro and mild erosion areas in the whole basin is about $85 \%$, and most of them are concentrated in the tranquil valley plain, which is the core zone of human activities and social and economic development in the whole basin, and the geomorphology is not obvious in the main terrain of plain and low mountain, which is the area with the most intense soil erosion intensity and area in the whole basin

\subsection{Structural differences}

An analysis of the proportion of soil erosion zones at all levels contributes to a more comprehensive understanding of the specific conditions of soil erosion in the region(Table 3). 
Table3 Soil erosion grading in Anning River basin in 199-2015 years

\begin{tabular}{ccccccc}
\hline \multirow{2}{*}{ Level } & modulus & \multicolumn{5}{l}{ Proportion of soil erosion zones at all levels } \\
\cline { 3 - 7 } & {$\left[\mathrm{t} /\left(\mathrm{km}^{2} \cdot \mathrm{a}\right)\right]$} & 1995 & 2000 & 2005 & 2010 & 2015 \\
\hline Micro & $<500$ & 64.26 & 60.93 & 60.96 & 63.42 & 62.61 \\
Mild & $500-2500$ & 20.29 & 23.53 & 22.03 & 22.99 & 21.87 \\
Moderate & $2500-5000$ & 10.10 & 10.07 & 10.59 & 9.54 & 10.30 \\
Strong & $5000-8000$ & 3.75 & 3.76 & 4.229 & 2.88 & 3.65 \\
Extremely & $8000-15000$ & 1.44 & 1.52 & 1.914 & 1.06 & 1.42 \\
Severe & $>15000$ & 0.16 & 0.19 & 0.283 & 0.11 & 0.15 \\
\hline
\end{tabular}

As can be seen from Table 3, the region's micro and Severe proportions occupy the largest and smallest ends of the entire basin, respectively, the change of proportional relationship in other intensity erosion areas was mild $>$ Moderate $>$ Strong $>$ Extremely. Taking the 2015-year data as an example, the micro erosion zone occupies the largest $62.61 \%$, the rates of mild, moderate, strong and extremely were $20.29 \%, 10.1 \%, 3.75 \%$ and $1.44 \%$, respectively, and decreased in turn, and only $0.16 \%$ of the Severe is minimal. The area of mild and below intensity erosion area in watershed area reached $84.03 \%$, which indicates that the intensity of soil erosion in the whole basin is at a mild level. Similarly, soil erosion in the region in 1995, 2000, 2005 and 2010 was at levels such as light erosion and below.

\subsection{Trend changes}

Unary linear regression can realize the regression fitting of each variable with time, and and predict its trend change. The model is as follows.

$$
X=\frac{n \times \sum_{i=1}^{n} i \times A_{i}-\left(\sum_{i=1}^{n} i\right)\left(\sum_{i=1}^{n} A_{i}\right)}{n \times \sum_{i=1}^{n} i^{2}-\left(\sum_{i=1}^{n} i\right)^{2}}
$$

In the model: $\mathrm{X}$ is slope, if $\mathrm{X}>0$ the value of raster cells increases, Increased amount of soil erosion. Otherwise, on the contrary.

The change of erosion ratio of different grades in 15 years shows that: The proportion of micro-erosion decreased by $1.65 \%$, while the proportion of mild and moderate soil erosion increased by $1.58 \%$ and $0.2 \%$ respectively. Overall analysis, the proportion of mild and below increased by $0.13 \%$. The raster proportions in strong, extremely strong and Severe erosion zones showed a decreasing state of change, falling by $0.1 \%, 0.02 \%$ and $0.01 \%$, respectively. The raster proportions in strong, extremely strong and Severe erosion zones showed a decreasing state of change, falling by $0.1 \%, 0.02 \%$ and $0.01 \%$, respectively. A comprehensive analysis shows that the increase in mild and below rates is mainly due to a decrease in the intensity and above. At the same time, the analysis of unary linear regression results also showed that the raster ratio of soil erosion increased by $91.67 \% \mathrm{X}<0$ in 15 years. $X>0$, the grid ratio of reduced soil erosion was only $8.32 \%$, and the region with a significant reduction in soil erosion accounted for the vast majority of the entire watershed area.

In summary analysis, the soil erosion in the whole Anning River basin has developed well in 15 years, and the soil erosion condition has been effectively treated, showing a clear trend of improvement.

\section{CONCLUSION}

Based on the RUSLE model, the temporal and spatial changes of soil erosion in the Anning River basin in the 1995-2015 are analyzed, and the main conclusions are as follows:

(1) From the spatial point of view, the soil erosion in the whole watershed area showed obvious difference of gradient change, and the soil erosion in the western region as a whole was more serious than that in the eastern region There are also different regional differences in spatial distribution of soil erosion areas at various levels. Extremely strong and sever accounts for the smallest and mainly distributed in the northwest of Mianning and the western region of Xichang. The position of strong and severe erosion zones and is mainly distributed in the middle and alpine regions on both sides of the tranquil valley plain. Mild and Micro eroded areas accounted for the highest proportion, distributed in the middle and low mountain area of the Valley plain.

(2) From the time point of view, the soil erosion area of each grade in the watershed area shows obvious change in the raster proportion over time. The raster ratio in only mild and moderate erosion zones in 1995-2015 years is an increased state of change. The proportion of the erosion zone raster of the remaining levels is reduced to varying degrees. Throughout the period, the situation of soil erosion in this area also showed a significant decrease in the trend of change, and its soil erosion status was effectively treated.

\section{References}

1. W. H. Wischmeier, D. D. Smith, Rainfall energy and its relationship to soil loss, Eos, Transactions American Geophysical Union, 1958.

2. M. Q. Chen, X. Wei, K. L. Zhang, etc, analysis of the Characteristics of Soil and Water Loss in Guizhou Province Based on CSLE, Journal of Soil and Water Conservation 31, 16-21(2017). 
3. K. Yi, S. Y. WANG, X. Wang, etc, The Characteristics of Spatial-temporal Differentiation of Soil Erosion Based on RUSLE Model: A Case Study of Chaoyang City, Liaoning Proince, SCIENCE GEOGRAPHICAL SINICA 35, 365-372(2015).

4. S. Cao, M. Y, Ouyang, W. J. Zhou, etc, Quantitative evaluation of soil erosion in Ningxiang City based on GIS and USLE, Journal of China Agricultural University 23, 149-157(2018).

5. J. Wang, W. M. Cheng, S. L. Qi, etc, Sensitive evaluation and spatial analysis of soil and water loss based on USLE and GIS:Taking Taihang Mountain area of Hebei Provice as an exeample, Geographical Research 33, 614-624(2014).

6. D. L .Li, J. Yang, W. H. Li, etc, Evaluation the sensitivity of soil erosion in the Yili River Valley based on GIS and USLE, Journal of Ecology 35, 942951(2016).

7. B. Y. Liu, Y. Xie, K. L. Zhang, etc, Soil Erosion Prediciton Model, Beijing Chinese Science and Technology Press, 2001.

8. B.T Liu, C. F. Song, Z. Shi. etc, Correction Algorithm of Slope Factor in Universal Soil Loss Equation in Earth-Rocky Mountain Area of Southwest China, Soil and water conservation in China, 49-51(2015).

9. F. Q. Huang, B. F. Di, C. .M. Huang, etc, Spatial Distribution of Soil Erosion in Liangshan, Sichuan Based on a New Equation to Estimate the Rainfall Erosivity, Journal of Mountains 31, 55-64(2013).

10. Y. H. Hu, B. T. Liu, C. F. Song, etc, Erosion Estimation in Liangshan Mountain Areas of Sichuan Province Based on USLE Model, Bulletin of Soil and Water Conservation 36, 232-236(2016).

11. H. Deng, Z. W. He, Y. Chen, etc, The Spatial Features of Soil Erosion in Mountain Environment Based on GIS and RUSLE 41, 669-679(2013).

12. B.T Liu, C. F. Song, Z. Shi. etc, Factors of soil and water conservation measures in Shishan District horizontal terraces of southwest soil, 36-39(2015). 